http://jmscr.igmpublication.org/home/ ISSN (e)-2347-176x ISSN (p) 2455-0450

crossref DOI: https://dx.doi.org/10.18535/jmscr/v8i1.30

Journal Of Medical Science And Clinical Research

\title{
Clinico-Cytological Evaluation of Cysticercosis in Kumaon Region of Uttarakhand: A 10 Years Study
}

\author{
Authors \\ Neha Yadav ${ }^{1}$, Usha Joshi ${ }^{2 *}$, Binay Kumar ${ }^{3}$, Shiv Prasad Yadav ${ }^{4}$ \\ ${ }^{1,2,3}$ Department of pathology, Government medical college Haldwani, Nainital, India \\ ${ }^{4}$ Department of Radiology, SGPGIMS,Lucknow, India \\ *Corresponding Author \\ Usha Joshi \\ Department of pathology, Government medical college Haldwani, Nainital, India
}

\begin{abstract}
Background: Cysticercosis is an increasingly common medical problem in the United States, especially in the Southwest. The clinical syndromes caused by T solium are categorized as either cysticercosis (cysts in various tissues including the brain) or taeniasis (intestinal tapeworm infection). Fine needle aspiration cytology [FNAC] plays a rapid, safe, and reliable role in prompt diagnosis of this disease.

Objectives: To evaluate the role of Fine needle aspiration cytology in diagnosis of cysticercosis and to analyse the clinical feature of cysticercosis in kumaon region.

Material and Methods: This retrospective study of ten years duration (January 2007 to March 2017) was carried out in a tertiary care centre of kumaon region of Uttarakhand. FNAC was performed on 43 Cases who presented with palpabe nodules at different sites. Subsequent excision biopsy was done whenever necessary.

Results: This study was conducted on 43 patients, presented with painless subcutaneous and intramuscular nodules at various sites. Majority of the patients were females. The most commonly affected sites were head and neck followed by abdominal wall. In most of the cases (20 cases; 46.51\%) clear/watery fluid like material was aspirated. Definitive diagnosis of Cysticercosis on FNAC was made in 32 cases. In Rest 11 cases (which were non diagnostic on FNAC) follow-up histopathological examination was done and confirmed diagnosis of Cysticercosis was made.

Conclusion: FNAC is a simple, sensitive, cost-effective, and rapid diagnostic tool for diagnosis of cysticercosis as cytological diagnosis is quite clear where the actual parasitic structures are identified in the smear.

Keywords: Cysticercosis, cases, diagnosis, Fine needle aspiration cytology, nodules.
\end{abstract}

\section{Introduction}

Cysticercosis is parasitic disease caused by larval stage of Taenia solium (pork tapeworm), the Cysticercus cellulosae. Man serves as the larval host, becomes infected by consumption of contaminated water or by uncooked vegetables/contaminated pork. In developing countries a high prevalence is noticed because of poor sanitary conditions and domestic pig raising without veterinary control. It is endemic in America, Africa and Asia. In India, it is more common in northern parts. Human cysticercosis 
commonly manifests as subcutaneous and intramuscular nodules. The most frequent sites affected are skeletal muscles, subcutaneous tissue, brain, ocular tissue, heart, liver and lungs. ${ }^{[1,2,3]}$ Preoperative diagnosis is done by radio imaging [CT scan and MRI] and serological tests [complement fixation test, hemagglutination, radioimmunoassay and ELISA]. Fine needle aspiration cytology (FNAC) provides direct and specific diagnosis, remains one of the ideal diagnostic procedures. In this study work was done to study the role of FNAC in the diagnosis of cysticercosis, and to study the clinical features suggestive of cysticercosis.

\section{Material and Methods}

It was a retrospective type of study of ten years duration (January 2007 to March 2017) carried out in a tertiary care centre of kumaon region of Uttarakhand. 43 Cases who presented with palpable nodules at different sites were taken. FNAC was performed with 22-gauge needle. Aspirated material was smeared on the glass slides and stained with Papanicolaou stain after fixation in $95 \%$ alcohol and with May-Grünwald-Giemsa (MGG) stain after air drying. On cytomorphological analysis 32 cases were diagnosed as cysticercosis. 11 cases that were non diagnostic on FNAC, their subsequent excision biopsy was done \& specimens sent for histopathology. Sections were made \& stained with haematoxylin and eosin stain.On histopathological examination; these 11 cases were come out to be Cysticercosis.

\section{Results}

The present study was conducted on 43 cases, presented with painless, slow growing subcutaneous/intramuscular nodules. These nodules were soft to firm in consistency, ranging in size from 0.5 to $4 \mathrm{cms} \&$ varied in duration from few days to years. Females (55.8\%) were affected more than males $(44.18 \%)$ and majority of cases were in $3^{\text {rd }}$ decade $(46.51 \%)$. The Most Commonly affected sites was head \& neck followed by abdominal cavity and least commonly affected site was lower extremity[Table-1].There were three cases $(6.97 \%)$ of cysticercosis of the oral cavity in this study [Figure-1]. Clear/watery fluid like material was aspirated in most of the cases $(20 ; 46.51 \%)$ and granular material was aspirated in $2(4.65 \%)$ cases [Table- 2].

In 32 cases definitive diagnosis of Cysticercosis was made on FNAC smears. These cases shows fragment of parasitic bladder wall which appears as granular, loose fibrillary sheath like structures. These fragments have multiple subcuticular cells with small blue pyknotic nuclei along with varying degree of mixed inflammatory cells infiltrate in the background [Figure-2]. Hooklets or scolices were not seen in any of the cases on cytology. In Rest 11 cases, larval fragments could not be identified on the aspirates, and the diagnosis of parasitic inflammation was suggested on the basis of other cytological findings such as clear fluid aspirate, presence of mixed inflammatory cell infiltrate or a typical granular dirty background. In these cases follow-up histopathological examination was done and confirmed diagnosis of Cysticercosis was made [Figure- 3].

Table 1: Sites of lesions

\begin{tabular}{|l|c|c|}
\hline Anatomical site & Number of cases & Percentage $(\mathrm{n}=43)$ \\
\hline Head \& Neck & 18 & $41.86 \%$ \\
\hline Abdominal wall & 11 & $25.58 \%$ \\
\hline Upper extremity & 6 & $13.95 \%$ \\
\hline Chest wall & 5 & $11.62 \%$ \\
\hline Back & 2 & $4.64 \%$ \\
\hline Lower extremity & 1 & $2.32 \%$ \\
\hline Total & 43 & $100 \%$ \\
\hline
\end{tabular}

Table 2: Materials aspirated on FNAC

\begin{tabular}{|l|c|c|}
\hline Aspirate & No. of cases & Percentage $(\mathrm{n}=43)$ \\
\hline Clear/watery fluid & 20 & $46.51 \%$ \\
\hline $\begin{array}{l}\text { Blood mixed } \\
\text { material }\end{array}$ & 12 & $27.9 \%$ \\
\hline $\begin{array}{l}\text { Greyish White } \\
\text { material }\end{array}$ & 05 & $11.62 \%$ \\
\hline Pus like material & 04 & $9.30 \%$ \\
\hline Granular material & 02 & $4.65 \%$ \\
\hline Total & 43 & $100 \%$ \\
\hline
\end{tabular}




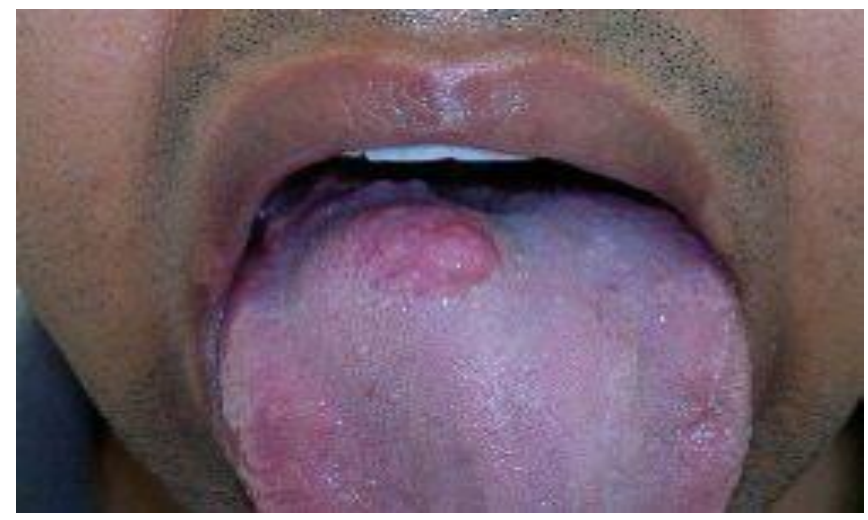

Figure 1: Clinical photograph showing nodular swelling on tongue

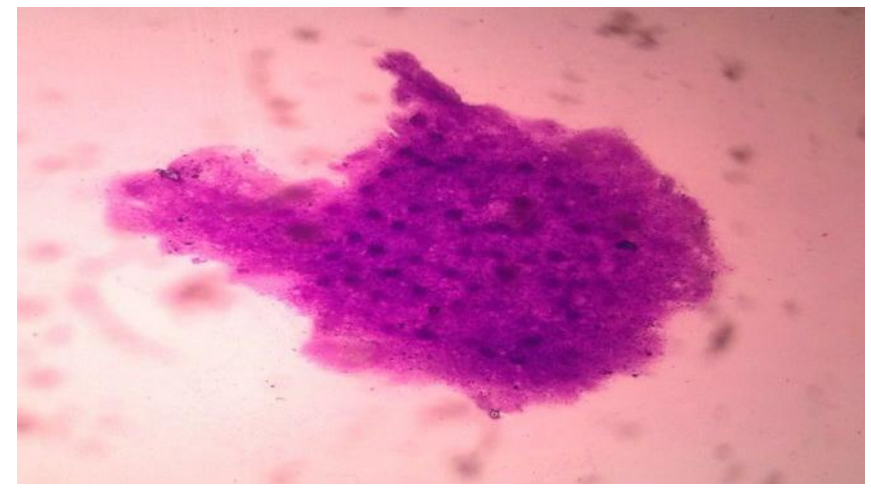

Figure 2: Smear showing a fibrillary fragment of bladder wall comprised of outer acellular pinkish layer, followed by subcuticular or tegumental cells with small pyknotic nuclei (MGG stain x100).

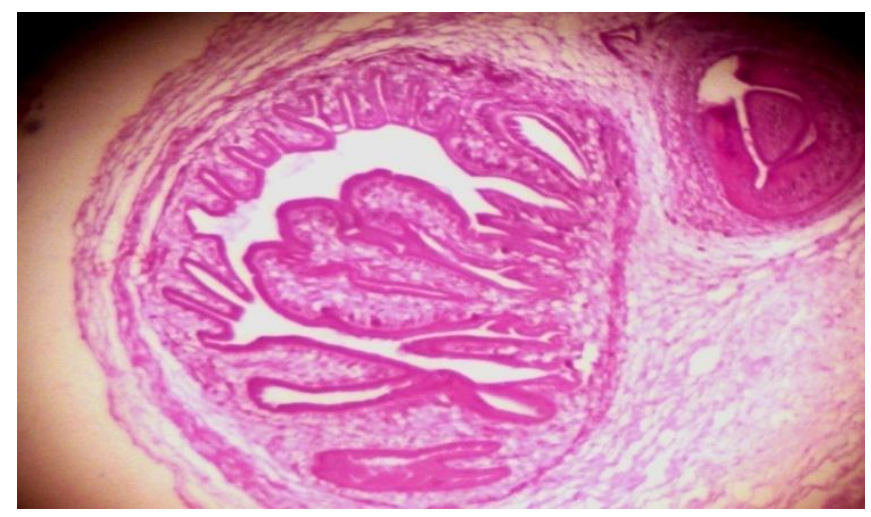

Figure 3: Photomicrograph of tissue section showing cysticercus larva enclosed in a thin fibrous cyst wall $(\mathrm{H} \& \mathrm{E}, \times 100)$

\section{Discussion}

In India the prevalence of cysticercosis ranges between $7-26 \%$. The larval stages of the parasitic cestode, Taenia solium causes infection of both humans and pigs. In this study head \& neck was most common site to be affected, as reported by
Handa et al. $^{[4]}$ There were $3(6.97 \%)$ cases of cysticercosis of the oral cavity which is an unusual location for cysticercosis as reported by Bern $\mathrm{C}$ et $\mathrm{al}^{[5]}$ in their study.FNAC may obviate the need for open biopsy and it is a low cost tool for preoperative diagnosis of cysticercosis. In a palpable subcutaneous/intramuscular nodule, aspiration of clear fluid on FNAC is a strong indicator of parasitic infection ${ }^{[4,6]}$. In our study aspirated material was clear fluid/watery fluid in majority of cases as reported by Handa et $\mathrm{al}^{[4]}$ and Pooja and Pratima. ${ }^{[7]}$ In cases where an actual parasitic structure is identified in the smears, the cytological diagnosis is quite straight forward.In this study, cytological diagnosis of cysticercosis was made in $32(74.41 \%)$ cases. Larval fragments could not be identified on the aspirates in Rest 11 cases. In these cases diagnosis of cysticercosis was made on subsequent biopsy and histopathological examination. Fully developed cysticerci are opalescent, milky white elongated to oval cysts having fluid and a single invaginated scolex. The scolex has a rostellum, four suckers and 22-32 small hooklets. On tissue sections, the cyst wall appears multilayered with an outer smooth and hyalinised, cuticular layer which is frequently thrown into projections, and covered with microtrichiae. There is a row of tiny tegumental cells beneath the tegument. The inner layer or parenchyma is loose and reticular, containing mesenchymal cells and calcareous corpuscles. ${ }^{[8][4][9]-[11]}$

\section{Conclusion}

Fine-needle aspiration cytology helps in early diagnosis of cysticercosis and helps in proper management of the disease .The cytological diagnosis of cysticercosis is quite possible in cases where actual parasite structures are identified in FNAC smears. In a few cases in which FNAC is non diagnostic, biopsy and subsequent histopathological examination helps in pinpointing the diagnosis. 


\section{References}

1. Saran RK, Rattan V, Rajwanshi A, Nijhawan R, Gupta SK. Cysticercosis of the oral cavity: Report of five cases and a review of literature. Int $\mathbf{J}$ Paediatr Dent. 1998;8:273-8.

2. Garcia HH, Del Brutto OH. Taenia solium cysticercosis. Infect Dis Clin North Am. 2000;14:97-119, ix.

3. De Souza PE, Barreto DC, Fonseca LM, de Paula AM, Silva EC, Gomez RS. Cysticercosis of the oral cavity: Report of seven cases. Oral Dis. 2000;6:253-5.

4. Handa U, Garg S, Mohan H. Fine needle aspiration in the diagnosis of subcutaneous cysticercosis. Diagn Cytopathol. 2008;36:183-7.

5. Bern C, Garcia HH, Evans C, Gonzalez AE, Verastegui $\mathrm{M}$, Tsang $\mathrm{VC}$, et al. Magnitude of the disease burden from neurocysticercosis in a developing country. Clin Infect Dis. 1999;29:1203-9.

6. Khurana N, Jain S. Cytomorphological spectrum of cysticercosis-A review of 132 cases. Indian J Pathol Microbiol 1999;42:69-71.

7. Kala P, Khare P. Fine-needle aspiration cytology as a diagnostic modality for cysticercosis: A clinicocytological study of 137 cases. J Cytol. 2014;31(2):68-72. doi:10.4103/0970-9371.138665

8. Gill M, Dua S, Gill P, Gupta V, Gupta S, Sen R, et al. Cytomorphological spectrum of subcutaneous and intramuscular cysticercosis: A study of 22 cases. J Cytol 2010;27:123-6.

9. Verma K, Kapila K. Fine needle aspiration diagnosis of cysticercosis in soft tissue swellings. Acta Cytol 1989;33:663-6.
10. Arora VK, Gupta K, Singh N, Bhatia A. Cytomorphologic panorama of cysticercosis on fine needle aspiration. A review of 298 cases. Acta Cytol 1994;38: 377-80.

11. Batrani M, Kaushal M, Chaturvedi NK, Yadav R. Fine needle aspiration of subcutaneous cysticercosis. Diagn Cytopathol 2010;38:347-8. 